\title{
NIILISMO EM NIETZSCHE: Suas Formas Psicológicas e Sua Relação Com a Verdade.
}

\author{
Jackson Daniel Adami ${ }^{1}$
}

\section{Resumo:}

Pretendemos, neste texto, inicialmente explorar as três formas do niilismo psicológico apontadas por Nietzsche. Para o pensador alemão, o niilismo era inescapável, dados os ideais valorizados na época que o acarretavam como conseqüência necessária. A busca incessante pela verdade levaria invariavelmente ao advento do niilismo em sua forma consumada. Parafraseando Nietzsche, poderíamos afirmar que a humanidade se empenhou numa milenar educação para a verdade que, finalmente, se proíbe crer em sua existência mesma. Durante o texto faz-se uma breve exposição sobre a transição que marca o suposto abandono dos ideais religiosos em prol dos ideais científicos e indica-se como, no fundo, mantiveram-se os mesmos fundamentos. A busca pela verdade obriga-se, em última instância, a questionar o valor mesmo da verdade. Em meio a essas investigações exploramos, ainda, de modo muito breve, alguns aspectos fisiológicos ensejadores/ decorrentes do niilismo.

Palavras chave: Niilismo - Ascetismo - Verdade.

\section{Abstract:}

We intend, in this text, initially explore the three forms of psychological nihilism noted by Nietzsche. For the German thinker nihilism was inescapable, given the ideals valued at the time that entailed as a necessary consequence. The unceasing pursuit of truth would invariably lead to the advent of nihilism in its intensest form. Paraphrasing Nietzsche, we could assert that humankind has committed to a millennial education about the truth, which, finally, it is forbidden to believe that it exists. Along this text there is a brief presentation about the transition that marks the supposed abandon of religious ideals in favor of scientific ideals and how they have remained the same in the background. The pursuit of truth obligate, ultimately, to question the value of the truth itself. Among these investigations we still explore, very briefly, some physiological aspects that occasion and/or come from nihilism.

Key-words: Nihilism - Asceticism - Truth

\footnotetext{
“- e vi uma grande tristeza descer sobre os homens. Os melhores deles cansaram-se de suas obras.

Proclamou-se uma doutrina, que uma fé acompanhava: 'tudo é vazio, tudo é igual, tudo foi!'

Decerto, fizemos a colheita; mas por que todos os frutos se nos apodreceram e enegreceram? O que caiu cá em baixo da má lua, na última noite?

Inútil foi todo trabalho, veneno tornou-se o nosso vinho, um mau-olhado engelhou e amarelou nossos campos e nossos corações.

Tornamo-nos, todos, secos; e, se caísse fogo sobre nós, seríamos reduzidos à cinza: sim, cansamos o próprio fogo.
}

\footnotetext{
${ }^{1}$ Mestrando em Filosofia pela Universidade Estadual do Oeste do Paraná da linha de pesquisa de Metafísica e Conhecimento. Licenciado em Filosofia pela Universidade Estadual do Oeste do Paraná. Bacharel em Psicologia pela Faculdade Assis Gurgacz.
} 
Todas as fontes se nos enxugaram, também o mar retirou-se. O solo quer fender-se, mas o abismo não nos quer tragar!

'Ah, onde há um mar, ainda, no qual possamos afogar-nos?' - assim soa nosso lamento - correndo por sobre brejos de águas pouco profundas.

Em verdade, já estamos cansados demais, para morrer; agora continuamos acordados e vivendo - em câmaras mortuárias!" - (Za/ZA; O Adivinho² ${ }^{2}$ pág. 166).

O que é o niilismo para Nietzsche? É a absoluta falta de sentido da existência. Nietzsche vê o niilismo como inescapável: "Por que o advento do niilismo é doravante necessário? Porque nossos valores até agora são aqueles mesmos que o acarretam como a sua última conseqüência; porque o niilismo é a lógica de nossos grandes valores e ideais pensada até o fim, [...]" (Fragmento póstumo; 11 [411] 4; novembro de 1887 - março de 1888). Mas como chegamos até isso?

Houve um tempo em que a sobrevivência era um sentido; o único sentido. Criaram-se mitos, crenças, religiões e filosofias; viveu-se e morreu-se por tais coisas, viu-se nisso também um sentido, uma finalidade. E a mais implacável das finalidades foi o além-mundo. O homem, deparando-se com as forças cegas da natureza, inconseqüentes e injustas, que, sem olhos, destruíam ou beneficiavam; percebendo o sofrimento inerente à existência, criou para si um reino da perfeição. Tal reino é um "para quê"; vive-se e aceita-se a vida em toda sua crueldade e sofrimento pela via da crença numa recompensa além-mundo. Conforme lemos no fragmento póstumo 9 [43] de Outono de 1887, a finalidade apareceu sempre como algo dado. Tendemos a nos perguntar “para quê?”. A religião oferece a salvação; mas, para alguns, não: a ciência guarda a verdade; o comportamento moral, virtude e felicidade; a linguagem busca comunicar, assim como o martelo, martelar; a árvore frutífera aí está para frutificar, e depois da morte costuma vir o luto.

No entanto “[...] compreende-se que, com o devir, nada se alcança, nada é alcançado... Portanto, a desilusão com um pretenso fim do devir como causa do niilismo: [...]" (Fragmento póstumo; 11 [99] novembro de 1887 - março de 1888). Um dia, o martelo vai quebrar, a árvore vai secar... um dia, a linguagem se tornará distorção, mentira a salvação, e a verdade escapará por uma fresta, a morte, quiçá, será ainda motivo de festa. Nenhum fim será atingido: esta é a realidade do devir, um processo que nunca pára e que se recria a cada

\footnotetext{
2 “O que conto é a história dos dois próximos séculos. Descrevo o que vem, o que não pode mais vir de outro modo: o advento do niilismo." (Fragmento póstumo ; 9 [35] Outono de 1887).
} 
instante, sem começo nem fim. Esta é a primeira forma de niilismo enquanto estado psicológico ${ }^{3}$.

A segunda forma do niilismo enquanto estado psicológico diz respeito à unidade. Uma sistematização do existir, uma organização na qual o homem se coloca como peça, na qual tudo é peça fundamental. Essa crença na unidade, na qual o homem tem "[...] o sentimento profundo de uma conexão com e dependência de um todo infinitamente superior a ele, um modo da divindade... 'o bem do universal exige a entrega do indivíduo'... mas, olhe aí, não existe nenhum tal universal!” (Fragmento póstumo; 11 [99] novembro de 1887 - março de 1888). Isso insinua uma sacralização do existir. Particularmente, consideramos esta forma do niilismo a mais complicada de apreender sob a perspectiva da filosofia nietzschiana, visto que ela parece ser exatamente o que Nietzsche entende por amor fati, o amor aos fatos, à existência como ela é: a vontade de que tudo aconteça de novo, do mesmo modo. Essa idéia do amor ao existir, associada à idéia de que tudo está em relação com tudo, dá a entender que o indivíduo está inserido em algo sumamente superior a ele e que somente recebe seu sentido a partir daí. No entanto, tendemos a entender que o foco da crítica de Nietzsche é a sistematização, isto é, pensar que a existência é um todo organizado e unívoco (livre de contradições), ou seja, um organismo, concebido no sentido da ciência, algo com um propósito, uma meta ou finalidade. Escreve ele:

\begin{abstract}
Guardemo-nos de pensar que o mundo é um ser vivo. [...] Sabemos aproximadamente o que é o orgânico; e o que há de indizivelmente derivado, tardio, raro, acidental, que percebemos somente na crosta da Terra, deveríamos reinterpretálo como algo essencial, universal, eterno, como fazem os que chamam o universo de organismo? Isso me repugna. Guardemo-nos de crer também que o universo é uma máquina; certamente não foi construído com um objetivo, e usando a palavra 'máquina' lhe conferimos demasiada honra. Guardemo-nos de pressupor absolutamente e em toda parte uma coisa tão bem realizada como os movimentos cíclicos dos nossos astros vizinhos; um olhar sobre a Via Láctea já nos leva a perguntar se lá não existem movimentos bem mais rudimentares e contraditórios, assim como astros de trajetória sempre retilínea e outras coisas semelhantes. A ordem astral em que vivemos é uma exceção; essa ordem e a considerável duração por ela determinada tornaram possível a exceção entre as exceções: a formação do elemento orgânico. O caráter geral do mundo, no entanto, é caos por toda a eternidade, não no sentido de ausência de necessidade, mas de ausência de ordem, divisão, forma, beleza, sabedoria e como quer que chamem nossos antropomorfismos estéticos. (FW/GC; $\$ 109$, grifos nossos)
\end{abstract}

\footnotetext{
3 "O niilismo como estado psicológico terá de se declarar primeiro quando procurarmos em todo acontecimento um 'sentido' que não há aí: [...]” (Fragmento póstumo; 11 [99] novembro de 1887 - março de 1888).
} 
Reforcemos: “[...] o mundo não é absolutamente nenhum organismo, mas sim o caos: [...]" (Fragmento póstumo; 11 [74] novembro de 1887 - março de 1888). Nietzsche critica essa noção de organismo, pois que dá ensejo à noção de algo que organiza, que possui a tarefa de pôr em ordem a existência ou que desde sempre a "criou" ordenadamente. Isto, por sua vez, permite responsabilizar esse princípio supremo, tirando da existência sua inocência. Nietzsche afirma que essa crença no todo organizado é fruto da ciência ateísta, que já não admite Deus, mas vê na existência uma unidade de finalidade:

\begin{abstract}
A contra-parte científica moderna da crença em Deus é a crença no todo como organismo: isso me repugna. Ora, o totalmente raro, o indizivelmente elevado, o orgânico, que só percebemos sobre a crosta da Terra, fazer dele o essencial, universal, eterno! Isso é sempre ainda humanização da natureza! (Fragmento póstumo; Primavera-Outono de 1881, nº11 [201] apud. Müller-Lauter; 1997, pág. 103, nota nº106; grifo nosso).
\end{abstract}

A contraparte científica vê tal organização, devido a seu antropomorfismo, isto é, à imposição de sua própria perspectiva sobre a vida. Nós, homens, fincamos nossa perspectiva na natureza; tomando-nos como organismos-coisas, vemos tudo como sendo organizado, no sentido apontado ${ }^{4}$; mas, para Nietzsche, não esqueçamos, somos um sopro na existência, uma formação apenas. O mundo, tomado de modo mais geral, é o caos, a falta de organização consistente; se há um certo nível de organização num ponto remoto da existência, ele é um mero incidente; não devemos jogar demasiada luz sobre ele, porque não define o caráter mesmo da existência. A unidade do todo, para Nietzsche, é refutada. Não há essa tal unidade organizada; no todo imperam o caos e o acaso, embora sempre de modo necessário. - A necessidade no caos é um ponto bastante controverso em Nietzsche. Ele alega, em prol dessa necessidade, que isso quer dizer tão somente que uma força é essa mesma força e não pode ser outra força. No entanto, pode-se entender que as regras da luta entre as forças, isto é, as próprias condições de possibilidade da luta, sejam uma espécie de organização, e não o caos. Poderia este, no âmbito de tais lutas, configurar-se na absoluta falta de necessidade de que a força mais forte vença? Nietzsche antecipa a crítica e defende-se:

Que a aparente "finalidade" ("a finalidade infinitamente superior a toda arte humana") é apenas a conseqüência daquela vontade de poder que transcorre em todo acontecer -

\footnotetext{
${ }^{4}$ Nesse 'fincar', além da antropomorfização, há também o caráter da utilidade, de incremento da força: "Não 'conhecer', mas sim esquematizar, impor ao caos tanta regularidade e formas quantas sejam suficientes à nossa necessidade prática.” (Fragmento póstumo; 14 [152] Primavera de 1888).
} 
que o tornar-se mais forte traz consigo ordenações que parecem semelhantes a um projeto-finalidade -

que os fins aparentes não são intencionais; o que acontece é que tão logo a supremacia [ Übermarcht] sobre um poder [Macht] menor seja alcançada, e o último trabalhe em função do maior, uma ordenação da hierarquia [des Rangs], da organização, há de despertar a aparência de uma ordenação de meio e fím. (Fragmento póstumo; 9 [91] Outono de 1887).

Desse modo, parece-nos que a ordem, isto é, a aparência de organização, segundo Nietzsche, seria algo acrescentado posteriormente, a partir da necessidade. Tudo ocorreria em meio ao caos, mas, ao olharmos para o acontecer caótico, nós, enquanto "unidades" interpretantes, atribuiríamos uma espécie de organização ao caos. O devir se dá de modo necessário (o que acontece tem que acontecer porquanto acontece): que nós atribuamos a vitória de um impulso ou interpretação à sua maior força parece ser acréscimo perspectivístico derivado de uma necessidade de impor ordem, motivos, algumas vezes finalidade.

Interessante pontuar que, para Nietzsche, esta segunda forma de niilismo psicológico parece decorrer de uma necessidade de valorização, um refúgio que endosse o valor do indivíduo, que se vê lançado no mar infinito da ausência de sentido. Escreve o filósofo: "O niilismo como estado psicológico declara-se, em segundo lugar, quando se postulou uma totalidade, uma sistematização, uma organização em todo acontecimento e sob todo acontecimento: de modo que a alma sequiosa de admiração e de veneração sacie-se na representação de conjunto de uma suprema forma de governo e de domínio [...]" (Fragmento póstumo; 11 [99] novembro de 1887 - março de 1888). Não que o homem não tenha valor algum, trata-se antes de atribuir a ele seu devido valor: "No fundo, o homem perdeu a crença em seu valor se, por meio dele, não age um todo infinitamente valioso: isto é, ele concebeu um tal fim para poder acreditar em seu valor." (Fragmento póstumo; 11 [99] novembro de 1887 - março de 1888). É inevitável precipitar-se na mais dura ausência de sentido, o niilismo é necessário, pois nossos valores o acarretam como conseqüência inescapável, como já pontuado por Nietzsche. Trata-se agora, tão somente, de atribuir valor ao homem pelo que ele é e não pelo que é através dele. Avaliar o homem pela finalidade para a qual supostamente contribui seria avaliar a finalidade e não o homem. E quando esta finalidade é posta por terra, como quer nos mostrar constantemente Nietzsche, ou seja, quando ela perde completamente seu valor, o homem, avaliado a partir daquela finalidade perde também o seu sentido. Mas vejam, com a finalidade o valor do homem nunca foi pensado; que seja pois, avaliado por si, pelo que é. Se não é fim, mas apenas meio, se não é terra firme, mas ponte, que seja, então, valorado como meio, como ponte. Assim pouco importa se é ponte para a doce terra 
prometida ou ponte para lugar nenhum. Seu valor será medido pelo que é e não pelo que é além de si; pois o que queremos valorar afinal?

A terceira e última forma do niilismo resulta da constatação das duas primeiras: “[...] com o devir, nada deve ser alcançado e [...] sob o devir, não impera [waltet] nenhuma grande unidade na qual o indivíduo deve submergir completamente como em um elemento de um supremo valor: [...]" (Fragmento póstumo; 11 [99] novembro de 1887 - março de 1888). Segundo Nietzsche, é aqui que se cria, como subterfúgio desesperado, um além-mundo. Este surge como fruto da resistência em aceitar o mundo dos fatos, em sua iminente falta de sentido, e se torna uma finalidade que dota de sentido e valor o mundo factual, ainda que de modo indireto e não por si mesmo, ou seja, o mundo só teria valor devido a uma finalidade que está para além dele próprio ${ }^{5}$. No entanto, tal mundo é interditado tão logo perceba-se que é fruto dessa resistência e que foi criado tão "[...] somente por necessidades psicológicas [...]" (Fragmento póstumo; 11 [99] novembro de 1887 - março de 1888). E eis que o niilismo se implanta: "[...] interdita-se toda espécie de via de escape para o mundo do além e para falsas divindades - mas não se suporta este mundo, que já não se está disposto a negar..." (Fragmento póstumo; 11 [99] novembro de 1887 - março de 1888). O niilismo consiste, agora, em não ter para onde fugir daquilo que se deseja irremediavelmente evitar: a falta de sentido.

Estas são as três linhas mais específicas do niilismo psicológico: fim, unidade e ser ${ }^{6}$. Para Nietzsche, quando desvalorizarmos essas três categorias, admitindo que não se aplicam ao todo, elas não serão mais nenhuma razão para desvalorizar o todo. Mas prossigamos em direção a uma caracterização mais geral do niilismo; vejamos como ele atua fisiologicamente como força desintegradora, em especial nos buscadores da verdade.

A filosofia, com os filósofos da phýsis, se contrapõe à mitologia num arroubo de busca pela verdade ${ }^{7}$, que culmina no Ser dos eleatas e possibilita a instauração do cristianismo como doutrina da verdade. Decai sobre o homem, então, aquilo que se convencionou chamar "idade das trevas", até que se engendra, a partir dela, o racionalismo moderno, que pretende retirar o

\footnotetext{
5 “[...] Nós medíamos o valor do mundo em categorias que diziam respeito a um mundo puramente fictício." (Fragmento póstumo; 11 [99] novembro de 1887 - março de 1888).

${ }^{6}$ Ser enquanto um Deus regente do além-mundo, ou mesmo enquanto o mundo da verdade, o Mundo do Ser, em oposição ao Mundo das Aparências. 'Em resumo, extirpamos de nós as categorias 'fimm', 'unidade', 'ser', com as quais incutimos um valor no mundo - e então o mundo aparece como sem valor..." (Fragmento póstumo; 11 [99] novembro de 1887 - março de 1888; grifo nosso).

${ }^{7}$ Não que os mitos tenham sido considerados falsos desde sua criação, a rigor, eles foram criados pra explicar acontecimentos e de fato acreditava-se na sua existência, há já neles uma vontade de verdade como necessidade de incremento de poder.
} 
homem dessa escuridão, trazendo-o à luz da razão. As ciências surgem em oposição ao ideal religioso. Esse confronto entre ciência e fé é ainda muito presente e em certas épocas foi extremamente acirrado, uma vez que há uma divergência fundamental em suas concepções. $\mathrm{Na}$ vertente religiosa temos a verdade recebida, concedida, dada por Deus. $\mathrm{Na}$ vertente científica, a verdade das investigações, a verdade conseguida, adquirida, por meio de pesquisas e experimentações.

Considerando essa divergência, Nietzsche aponta um enigma: no aforismo 58 de Além do Bem e do Mal, o filósofo comenta como a sociedade moderna se tornou indiferente à religião, aceitando seus usos e ritos, deles participando como de qualquer costume social, por mais que, no fundo, fosse quase inconscientemente, ateísta. Entre esses indiferentes não estão apenas os comerciantes, mas também os "“...] eruditos laboriosos e todos os pertencentes à universidade (com exceção dos teólogos, cuja existência, e possibilidade de lá existir, fornece aos psicólogos enigmas cada vez mais numerosos e mais sutis).” (JGB/BM; §58).

O que levaria um teólogo, com seu ideal ascético, antinatural, a encontrar seu último refúgio na universidade, o local onde se busca a verdade, onde a ciência é entronizada, ao reduto dos eruditos, dos espíritos-livres, que refutaram peremptoriamente a concepção de verdade da religião? Evocamos então uma passagem da Gaia Ciência:

\begin{abstract}
Mas já terão compreendido onde quero chegar, isto é, que a nossa fé na ciência repousa ainda numa crença metafísica - que também nós, que hoje buscamos o conhecimento, nós, ateus e anti-metafísicos, ainda tiramos nossa flama daquele fogo que uma fé milenar acendeu, aquela crença cristã, que era também de Platão, de que Deus é a verdade, de que a verdade é divina... (FW/GC; §344).
\end{abstract}

Isto é, a busca pela verdade, tão apregoada pela religião, leva-a à dissolução; o ideal ascético radicalizado conduz ao próprio colapso “[...] - é a apavorante catástrofe de uma educação para a verdade que dura dois milênios, que por fim se proíbe a mentira de crer em Deus.[...] 'patere legem, quam ipse tulisti' [sofre a lei que tu mesmo propuseste]." (GM/GM; III; §27). O que fazem, pois, os teólogos nas universidades? O mesmo que os cientistas: buscam a verdade ${ }^{8}$. Se, em Além do Bem e do Mal, os teólogos na universidade eram um enigma para Nietzsche, na Genealogia da Moral esse enigma é resolvido; Nietzsche mostra que na universidade, especialmente entre os cientistas, existem apenas teólogos, sob os mais

\footnotetext{
${ }^{8}$ Mas por que insistem? "Pois assim é o homem: um artigo de fé poderia lhe ser refutado mil vezes - desde que tivesse necessidade dele, sempre voltaria a tê-lo por 'verdadeiro',[...]" (FW/GC; §347). Mas não pensemos que com os cientistas seja diferente; o que atua em ambos os casos - em todos os casos - é vontade de poder.
} 
variados disfarces, até mesmo sob o disfarce do ateísmo. Pois os cientistas são herdeiros da doutrina do Ser dos eleatas, e a ciência é seu fruto mais tardio: “[...] - se jamais fui um decifrador de enigmas, quero sê-lo com esta afirmação!” (GM/GM; III; §24).

Segundo Nietzsche, “[...] (a inexequibilidade de uma interpretação de mundo à qual foi dedicada monstruosa força ${ }^{9}$ - desperta a desconfiança de que todas as interpretações de mundo sejam falsas -) [...]" (Fragmento póstumo; 2 [127] Outono de 1885 - Outono de 1886) ${ }^{10}$. Aqui, vemos o primeiro passo histórico do niilismo: o abandono de algo que se configurou como sentido para a existência, durante milênios. O imediato segundo passo é a valorização da moral pela moral, como sombra de Deus; ou seja, mesmo este tendo perdido sua força de fundamentação da vida, ainda seguiremos a moralidade no sentido religioso, alguma moral, pois supõe-se que ela seja útil. No entanto, tudo isso só faz com que caiamos mais fundo no poço do niilismo. A compaixão, a negação de si mesmo, o sacrifício e altruísmo, valores morais oriundos da religiosidade cristã, são transformados e no entanto reafirmados, na filosofia moderna, sob a figura de Schopenhauer, cujo pensamento deprecia a vida por meio do pessimismo mais enraizado. "Precisamente nisso enxerguei o grande perigo para a humanidade, sua mais sublime sedução e tentação - a quê? ao nada? -;" (GM/GM; Prólogo, §5).

Nietzsche vê em Schopenhauer o clímax do pessimismo; vê, nele, o áugure do niilismo, em que a busca pela verdade transforma-se em recusa à vida. A compaixão se transforma em recusa completa de si. Negam-se os instintos. Schopenhauer é a mais pura expressão do cansaço frente à vida. Esta, sem o engano da religião e da crença metafísica num além-mundo, torna-se insuportável, mas já não se pode voltar atrás: o mundo metafísico está para sempre negado. Assim, conclui: "Um niilista é o homem que ajuíza que o mundo que é não deveria ser e que o mundo que deveria ser não existe.” (Fragmento póstumo; 9 [60] Outono de 1887). Niilista se chama àquele que está fisiologicamente esgotado, para quem só há sentido no nada, na negação de tudo; ele quer descanso da vida" . "A visão do homem

\footnotetext{
${ }^{9}$ Imaginemos o quanto de força foi necessário para a repressão dos instintos mais vorazes de todos os santos; quanta crueldade para consigo. É preciso muita força para parar a natureza e desviá-la de seu curso.

10 “[...]: o páthos do 'em vão' é o páthos do niilista - [...]” (Fragmento póstumo; 9 [60] Outono de 1887). "O páthos seria um sentimento [...]" (Nota nº77 de Paulo César de Souza à tradução de A Gaia Ciência). Podemos conceituar pathos como sendo um conjunto de sentimentos que definem maneiras de agir, estados de ânimo e disposições de modos de ser ante ao mundo.

${ }^{11}$ Para Nietzsche, o niilismo assume duas formas; podendo ser passivo ou ativo, ele é ambíguo. A forma de niilismo que atribui a Schopenhauer é o niilismo passivo, dissolutor, o budismo que almeja ao nada, que não mais ataca. Ela se opõe ao niilismo do tipo ativo que visa destruir, que é uma força que se expande e por isso precisa de espaço, que destroça as convicções vigentes por serem inadequadas para si, limitantes. $(C f$. Fragmento póstumo; 9 [35] Outono de 1887). A forma passiva de niilismo, presente em Schopenhauer,
} 
agora cansa - o que é hoje o niilismo, se não isto?...” (GM/GM; I; §12). Resposta: “ - Não o temor $^{12}$; mas sim que não tenhamos mais o que temer no homem; [...]" (GM/GM; I; §11). Esse é agora o nosso sofrimento em relação ao homem: ele está esgotado, não nos causa nenhum temor, pois não mostra nenhum sinal de força ou vigor, de vontade implacável para a vida, de ânsia de domínio; faltam-lhe recursos para a vida desprovida de uma "causa primeira". Como poderia tal homem, melhorado, amansado, niilizado (viciado em niilina ${ }^{13}$ ), alçar suas gerações ao futuro, se não tem forças para manter-se de pé?

$\mathrm{Na}$ filosofia, Schopenhauer parece ser o mais imerso passo niilismo adentro. O homem moderno distancia-se cada vez mais da metafísica e da religiosidade para lançar-se ao âmbito das ciências positivistas. O homem já não encontra em si autoridade para fundamentar o sentido da vida no além-mundo. Talvez por isso a ciência, no século XX, angarie enormes avanços - ela se torna o novo "para quê?" da humanidade.

Mas Nietzsche ainda guarda o golpe final. Falta o niilismo consumado até a medula. Ele aniquilará o último repasto do ideal ascético: justamente a ciência. O homem, que antes se refugiava nas religiões, poderia ainda conservar o sentido da existência buscando a verdade não mais no além-mundo, mas aqui e agora, através das ciências. No entanto, no pensamento nietzschiano, até mesmo as ciências são refutadas e todo o mundo dos sentidos torna-se ilusório. Mas Nietzsche não refuta apenas a pretensa veracidade científica; ele ainda a associa com um desejo de morte. Afirma, incisivamente, que até mesmo os ateus, anticristãos e os mais céticos filósofos partilham do ideal ascético, isto é, do ideal dos sacerdotes, que buscam a verdade e pregam a mortificação dos instintos. Para Nietzsche, os eruditos (ateus, céticos etc.) estimam a verdade acima de qualquer coisa; no entanto, como foi dito, ignoram que tal supervalorização da verdade provém da moral religiosa, ascética e antinatural, e esta, por sua vez, deriva da busca pelo Ser, do anseio pelo mundo da verdade, pelo mundo do "em si". Dessa flama os eruditos retiram seu fogo. Na Gaia Ciência, §344, lemos: "Vontade de

embora represente um estágio muito avançado, ainda não é a forma consumada do niilismo, pois, neste caso, o homem ainda almeja ao nada; ele vê um sentido no nada: "[..] o homem ainda preferirá querer o nada a nada querer..." (GM/GM; III; §28). Nietzsche vê nisso que “[...] a vontade mesma estava salva."(GM/GM; III; §28). E querer o nada é ainda uma forma de escapar ao niilismo consumado, pois “[...]; qualquer sentido é melhor que nenhum; [...]" (GM/GM; III; §28). O niilismo, para Nietzsche, é o maior dos venenos, é o sentimento do "em vão". O pessimismo de Schopenhauer constitui-se como niilismo passivo e desintegrador, que denota "[...] um sinal de força insuficiente [incapaz de produzir para si], novamente um fim, um porquê, uma crença." (Fragmento póstumo; 9 [35] Outono de 1887). Não obstante, ainda atua aí um sentido, uma força, isto é, vontade de potência.

${ }^{12}$ Nietzsche se refere, aqui, ao temor exercido pelos bárbaros, as bestas louras.

13 "[...] uma dinamite do espírito, uma niilina russa recém-descoberta, um pessimismo bonae voluntatis [de boa vontade], que não apenas diz Não, quer Não, mas - horrível pensamento! - faz o Não.” (JGB/BM; §208). 
verdade - poderia ser uma oculta vontade de morte." ${ }^{14}$. A afirmação surge quando da ligação proposta entre o ideal ascético, o ideal da antinatureza, e o ideal do erudito os quais partilhariam a busca pela verdade ${ }^{15}$. Mas como consegue Nietzsche estabelecer tal ponte? Enquanto erudito, filólogo, não teria ele sofrido, ao menos por algum tempo, desse mesmo mal, isto é, da busca pela verdade a todo custo ${ }^{16}$ De fato, ele assim se compreende e se afirma: " - Aquele que aqui toma a palavra, [...] o primeiro niilista consumado da Europa, que, todavia, já viveu, ele mesmo, o niilismo em si até o fim, [...]” (Fragmento póstumo; 11 [411] 3; novembro de 1887 - março de 1888). E, em consequência, deve dizer: "Só tardiamente tem-se coragem para aquilo que se sabe propriamente. Que até agora eu tenha sido radicalmente niilista, eis o que só há pouco me confessei: [...]" (Fragmento póstumo; 9 [123] Outono de 1887). Nietzsche só consegue enxergar-se como niilista quando está prestes a superar o niilismo ${ }^{17}$.

Ele também fora um buscador da verdade ${ }^{18}$; esteve do lado das ciências. Em Humano, Demasiado Humano, isto se revela em algumas passagens, panegíricos ao método científico e à sua objetividade, nas quais buscaria eliminar os preconceitos incrustados na razão.

Pode continuar a nos reger o hábito que herdamos de avaliar, amar, odiar erradamente, mas sob o influxo do novo conhecimento crescente ele se tornará mais fraco: um novo hábito, o de compreender, não amar, não odiar, abranger com o olhar, pouco a pouco se implanta em nós no mesmo chão, e daqui a milhares de anos

\footnotetext{
${ }^{14}$ Para Nietzsche, a concepção de um lugar como o céu, um lugar perfeito, eterno e imutável é a antítese do mundo terreno mutável; e o desejo de ir para um lugar como esse revela uma negação e uma recusa da vida como ela é; logo, trata-se de um desejo de morte, de suprimir a vida por uma hipótese além-mundo fictícia e pouco plausível (Cf. Fragmento póstumo; 14 [168] C; Primavera de 1888: "[...] o instinto do cansaço da vida, e não o da vida, criou o outro mundo."). Os céticos e ateus presumem ter fugido da crença religiosa, no entanto esquecem que a supervalorização da verdade é o maior trunfo da religião. Nietzsche faz a ponte entre busca pela verdade e busca pela morte, pelo mundo eterno e imutável, seja ele céu, seja ele o mundo cientificamente analisado, mapeado, funcionando de acordo com leis. Não obstante, a busca radical pela verdade revela a inexistência da verdade, o caráter perspectivo de todo existir, e, finalmente, a perda total de propósito do cientista, do cético e do ateu, buscadores da verdade: eis que surge o niilismo como o mal de seu tempo. A falta de sentido que atrofia o homem e o faz definhar até a extinção - a vontade de verdade no homem cético resultando na própria aniquilação dessa vontade.

15 “Ambos, ciência e ideal ascético, acham-se no mesmo terreno - já o dei a entender -: na mesma superestimação da verdade (mais exatamente: na mesma crença na inestimabilidade, incriticabilidade da verdade), e com isso são necessariamente aliados - [...]" (GM/GM; III; 25).

16 "“A todo custo': oh, nós compreendemos isso muito bem, depois que ofertamos e abatemos uma crença após a outra nesse altar!” (FW/GC; §344).

17 "Sombrio, eu caminhava, recentemente, no lívido crepúsculo - sombrio e crispado, mordendo os lábios. Não apenas um sol se havia posto para mim.” (Za/ZA; Da Visão e Do Enigma, 1; pág. 191).

${ }^{18}$ Muito embora não possamos dizer que ele acreditava que um dia a alcançaria, visto que nele sempre parece haver um ar de desconfiança ante as verdades absolutas. "[...] o páthos de possuir a verdade vale hoje bem pouco em relação àquele outro, mais suave e nada altissonante, da busca da verdade, que nunca se cansa de reaprender e reexaminar." (MAI/HHI; §633). Cf. também os parágrafos 634 e 635 da mesma obra, onde Nietzsche vê o aprimoramento do método como consequiência da busca científica, de nenhum modo menos importante que os resultados obtidos.
} 
talvez seja poderoso o bastante para dar à humanidade a força de criar o homem sábio e inocente (consciente da inocência), da mesma forma regular como hoje produz o homem tolo, injusto, consciente da culpa - que é, não o oposto, mas o precursor necessário daquele ${ }^{19}$.(MAI/HHI; §107).

Aqui, constatamos uma fase de seu pensamento na qual Nietzsche está em busca do conhecimento, ainda que deseje evitar toda a tendenciosidade dos preconceitos humanos infiltrados na ciência e na filosofia. Percebe-se uma deliberada tentativa de "não interpretar", mas tão somente abranger com o olhar, sem julgar. Numa das obras mais tardias, onde seu pensamento atinge, a nosso ver, o ápice da maturidade, lemos:

\begin{abstract}
Eu conheço tudo isso talvez de perto demais: a venerável abstinência de filósofo a que obriga tal $\mathrm{fe}^{20}$, o estoicismo do intelecto, que termina por proibir-se tão severamente o Não quanto o Sim, o querer deter-se ante o factual, ante o factum brutum [...] a renúncia à interpretação (a violentar, ajustar, abreviar, omitir, preencher, imaginar, falsear e o que mais seja próprio da essência do interpretar) grosso modo, isto expressa ascetismo da virtude, tão bem quanto qualquer negação da sensualidade (é, no fundo, apenas uma modalidade desta negação). Mas o que força a isto, a incondicional vontade de verdade, é a fé no próprio ideal ascético, mesmo como seu imperativo inconsciente, não haja engano a respeito - é a fé em um valor metafísico, um valor em si da verdade, tal como somente esse ideal garante e avaliza (ele se sustenta ou cai com esse ideal). (GM/GM; III; §24).
\end{abstract}

A negação da interpretação (ou seja, o amor à objetividade) leva diretamente ao niilismo; tal ascetismo, o asseio do intelecto, que almeja a determinação precisa dos “objetos", leva-nos ao nada. A objetividade radicalizada, a busca pelo "em si" das coisas, força a negar a própria coisa, pois, retirado aquilo que nossa interpretação atribui a elas, nada resta. Afirma Nietzsche: “A 'coisa em si' é um contrassenso. Se deixo de pensar em todas relações, em todas as 'propriedades', em todas as 'atividades' de uma coisa, então não sobra a coisa: [...]" (Fragmento póstumo; 10 [202] Outono de 1887). Isto vale para a metafísica, tanto quanto vale para a ciência. Reforcemos: "[...] não há nenhuma coisa sem outras coisas [...]" (Fragmento póstumo; 2 [85] Outono de 1885 - Outono de 1886).

Aqui começamos, porém, a delinear a via de escape frente ao niilismo, a saber, o perspectivismo. Tudo é interpretação; nossos sentidos são tão somente o modo como interagimos com o "mundo", o modo como distorcemos esse "mundo", - ou seja, o modo

\footnotetext{
${ }^{19}$ Notemos que Nietzsche não nega o homem contaminado pelos preconceitos, mas o vê como necessário para o advento de uma espécie de homem aprimorada em sua busca pela verdade. Negar o outro tipo de homem seria negar também este; em suma, negar a menor partícula do universo é negá-lo por completo; e isto iria de encontro ao amor fati. Por isso, em Nietzsche, não há oposições; uma coisa surge de seu oposto $(C f$. JGB/BM; $\S 2$ e MAI/HHI; §1), e a oposição é mera aparência. "O não-poder-contradizer prova uma incapacidade, não uma 'verdade'." (Fragmento póstumo; 14 [152] Primavera de 1888).

${ }^{20}$ Trata-se da fé na verdade.
} 
como interpretamos as configurações contingentes - para que façam sentido; isto é, para que tomem o sentido de um mundo. Trata-se, desde a base, de transformar um estímulo nervoso em imagem; não impera nada de verdadeiro e de "em si" por trás da imagem. E, assim, toda a busca pelo conhecimento objetivo culmina no vácuo. "Sabemos que a destruição de uma ilusão ainda não traz como resultado nenhuma verdade, mas sim apenas um bocado de ignorância a mais, uma extensão de nosso 'espaço vazio', um acréscimo de nosso 'deserto' -" (Fragmento póstumo; 35 [47] maio - julho 1885). A conseqüência é clara: “Algum dia, gritarás: Tudo é falso!” (Za/ZA; Do Caminho do Criador, pág. 90).

Afirma Nietzsche: “A duração, com um 'em vão' sem fim e sem objetivo, é o pensamento mais paralisante, especialmente quando se compreende que se é iludido e, mesmo assim, não se tem o poder de não se deixar iludir." (Fragmento póstumo; 5 [71] 5; Verão de 1886 - Outono de 1887). O que seria este pensamento mais paralisante? O niilismo consumado; neste se é iludido e, mesmo assim, não se tem o poder de não se deixar iludir, pois tudo é ilusão: nenhum Deus, nenhuma verdade, nenhuma finalidade. Como escapar a isto?

\section{Referências bibliográficas}

MÜLLER-LAUTER, W. A Doutrina da Vontade de Poder em Nietzsche. Trad. Osvaldo Giacóia. São Paulo: Anna Blume, 1997.

NIETZSCHE, Frederich. Wilhelm. Acerca da Verdade e da Mentira; O Anticristo; Tradução: Heloísa da Graça Burati. - São Paulo: Rideel, 2005. - Biblioteca Clássica.

A Gaia Ciência; tradução, notas e posfácio de Paulo César de Souza; São Paulo, Companhia das Letras, 2001; $4^{\mathrm{a}}$ reimpressão.

. Além do Bem e do Mal: prelúdio a uma filosofia do futuro; tradução, notas e posfácio Paulo César de Souza. São Paulo: Companhia das Letras, 2005; $7^{\mathrm{a}}$ reimpressão.

. Assim Falou Zaratustra: Um livro para todos e para ninguém; trad. Mario da Silva. 16 edição. Rio de Janeiro: Civilização Brasileira, 2007.

. Fragmentos Póstumos: Volumen III (1882 - 1885). Edición española dirigida por Diego Sánchez Meca. Traducción, introducción y notas de Diego Sánches Meca y Jesús Conill; Madrid, Tecnos (Grupo Anaya S.A.), 2010. 
. Fragmentos Póstumos: Volumen IV (1885 - 1889). Edición española dirigida por Diego Sánchez Meca. Traducción, introducción y notas de Juan Luis Vermal y Joan B. Llinares; Madrid, Tecnos (Grupo Anaya S.A.), 2008 - 2a edición.

Genealogia da Moral: uma polêmica; tradução, notas e posfácio de Paulo César de Souza. São Paulo: Companhia das Letras, 1998; 10ª reimpressão.

. Humano, Demasiado Humano: Um livro para espíritos livres; tradução, notas e posfácio de Paulo César de Souza; São Paulo, Companhia das Letras, 2000; $4^{\mathrm{a}}$ reimpressão.

ONATE, Alberto Marcos. Vontade de Verdade: uma abordagem genealógica. Cadernos Nietzsche nº 1, págs. 07-32. São Paulo: Ed. GEN, 1996.

THE NIETZSCHE CHANNEL. Concordance between The Will to Power and Sämtliche Werke: Kritische Studienausgabe. Disponível em: <http://www.thenietzschechannel.com/notebooks/concordance/concordance.htm>

FRANKL, Viktor E. Em Busca de Sentido: um psicólogo no campo de concentração. Tradução de Walter O. Schlupp e Carlos C. Aveline; revisão técnica de Helga H. Reinhold, $2^{\mathrm{a}}$ ed. São Leopoldo, Editora Sinodal; Petrópolis, Editora Vozes, 2007, 24ª edição (revisada). 